\title{
Diaphragm function and weaning from mechanical ventilation: an ultrasound and phrenic nerve stimulation clinical study
}

\author{
Martin Dres ${ }^{1,2^{*}}$, Ewan C. Goligher ${ }^{3,4}$, Bruno-Pierre Dubé1,5, Elise Morawiec ${ }^{2}$, Laurence Dangers ${ }^{1,2}$, \\ Danielle Reuter ${ }^{2}$, Julien Mayaux ${ }^{2}$, Thomas Similowski ${ }^{1,2}$ and Alexandre Demoule ${ }^{1,2}$
}

\begin{abstract}
Background: Diaphragm dysfunction is defined by a value of twitch tracheal pressure in response to magnetic phrenic stimulation (twitch pressure) amounting to less than $11 \mathrm{cmH}_{2} \mathrm{O}$. This study assessed whether this threshold or a lower one would predict accurately weaning failure from mechanical ventilation. Twitch pressure was compared to ultrasound measurement of diaphragm function.

Methods: In patients undergoing a first spontaneous breathing trial, diaphragm function was evaluated by twitch pressure and by diaphragm ultrasound (thickening fraction). Receiver operating characteristics curves were computed to determine the best thresholds predicting failure of spontaneous breathing trial.

Results: Seventy-six patients were evaluated, 48 (63\%) succeeded and 28 (37\%) failed the spontaneous breathing trial. The optimal thresholds of twitch pressure and thickening fraction to predict failure of the spontaneous breathing trial were, respectively, $7.2 \mathrm{cmH}_{2} \mathrm{O}$ and $25.8 \%$, respectively. The receiver operating characteristics curves were 0.80 (95\% Cl 0.70-0.89) for twitch pressure and 0.82 (95\% Cl 0.73-0.93) for thickening fraction. Both receiver operating characteristics curves were similar $\left(p=0.83\right.$ ). A twitch pressure value lower than $11 \mathrm{cmH}_{2} \mathrm{O}$ (the traditional cutoff for diaphragm dysfunction) predicted failure of the spontaneous breathing trial with a sensitivity of $89 \%$ (95\% Cl $72-98 \%)$ and a specificity of $45 \%$ (95\% Cl 30-60\%).

Conclusions: Failure of spontaneous breathing trial can be predicted with a lower value of twitch pressure than the value defining diaphragm dysfunction. Twitch pressure and thickening fraction had similar strong performance in the prediction of failure of the spontaneous breathing trial.
\end{abstract}

Keywords: Liberation, Ventilator, Diaphragm, Weakness, Ultrasound, Extubation

\section{Background}

Diaphragm dysfunction is common in critically ill patients exposed to mechanical ventilation [1]. It can occur soon after intubation [2]. It can also occur later, where it may be a consequence of intensive care unit acquired weakness or the result of the specific time-dependent impact of mechanical ventilation on the diaphragm [3-7], a phenomenon referred to as

\footnotetext{
*Correspondence: martin.dres@aphp.fr

2 Service de Pneumologie et Réanimation Médicale (Département "R3S") AP-HP, Groupe Hospitalier Pitié-Salpêtrière Charles Foix, 47-83 boulevard de l'Hôpital, 75013 Paris, France

Full list of author information is available at the end of the article
}

ventilator-induced diaphragm dysfunction [8]. Diaphragm dysfunction is associated with increased mortality $[2,3,9]$ and delayed liberation from mechanical ventilation $[3,4,10,11]$.

Diaphragm dysfunction manifests as a reduced capacity to generate inspiratory pressure and flow [12]. This can be assessed in term of the negative pressure swing measured at the opening of an endotracheal tube in response to bilateral phrenic nerve stimulation (Ptr,stim) [1]. Outside of the intensive care context, a Ptr,stim value amounting to less than $11 \mathrm{cmH}_{2} \mathrm{O}$ is considered indicative of diaphragm dysfunction [12-14]. In critically ill patients, this value of $-11 \mathrm{cmH}_{2} \mathrm{O}$ has proven useful 
from a prognostic point of view. In a prospective study of ICU patients in whom Ptr,stim was measured at time of weaning, patients with a Ptr,stim below the $11 \mathrm{cmH}_{2} \mathrm{O}$ threshold were less likely to survive to discharge from the ICU or hospital than those with a Ptr,stim above this threshold [3]. Yet, lower Ptr,stim values are commonly encountered in ICU patients at various points of their ICU stay $[2-4,15]$ and two recent studies have reported successful weaning from mechanical ventilation despite lower values of Ptr,stim [3, 4]. Therefore, our hypothesis was that the Ptr,stim threshold value used to define diaphragm dysfunction $\left(-11 \mathrm{cmH}_{2} \mathrm{O}\right)$ would be not necessarily the best threshold that allows successful or failed weaning from mechanical ventilation. The present study was designed to identify the optimal Ptr,stim value to predict failure of the spontaneous breathing trial. In view of the recently reported utility of diaphragm thickening fraction (TFdi) [16] to predict failure of the spontaneous breathing trial, the predictive value of this variable was also evaluated.

\section{Patients and methods}

This study was an ancillary analysis of a study prospectively conducted over 9 months (November 1, 2014, to July 31,2015$)$ in a medical 10-bed ICU. Human research ethics committee approval for the study was provided by the Comité de Protection des Personnes-Ile de France 6 (ID RCB: 2014-A00715-42). Informed consent was obtained from all patients or their relatives. Data from this cohort have been previously published [3, 17].

\section{Patients}

Patients were eligible for inclusion if they had been intubated and ventilated for at least $24 \mathrm{~h}$ and if they met predefined readiness-to-wean criteria on daily screening [18] and were therefore ready for a first spontaneous breathing trial (Additional file 1: readiness criteria to initiate a spontaneous breathing trial). Readiness-towean criteria were searched for while patients were ventilated on existing mechanical ventilation setting prior to spontaneous breathing trial (SBT). Patients with clinical factors potentially interfering with phrenic nerve stimulation, who had a tracheostomy, or who were unable to follow simple orders were excluded (Additional file 1: exclusion criteria).

\section{Measurements}

All measurements were taken a few minutes before starting the SBT. Phrenic nerve stimulation was performed while patients were briefly disconnected from the ventilator (Additional file 1: description of the phrenic nerves stimulation technique), and diaphragm ultrasound (Additional file 1: description of the ultrasound technique) was conducted while patients were mechanically ventilated under pressure support ventilation with ventilator settings decided by the attending physician. In our unit, pressure support level is set in order to provide a tidal volume of $6-8 \mathrm{ml} / \mathrm{kg}$ of ideal body weight without any sign of acute respiratory distress or discomfort. Positive end-expiratory pressure is set at $5 \mathrm{cmH}_{2} \mathrm{O}$.

Diaphragm function was assessed in terms of changes in tracheal pressure during a magnetic stimulation (Ptr,stim), as described elsewhere $[2,4,5,14,15]$. Stimulations were delivered at the maximum intensity allowed by the stimulator $(100 \%)$ known to result in supramaximal diaphragm contraction in most patients $[2,10,13,15$, 19]. Diaphragm ultrasound was conducted using a 4-12$\mathrm{MHz}$ linear array transducer (Sparq ultrasound system, Philips, Philips Healthcare, MA, USA). Diaphragm thickness was measured at end-expiration (Tdi,ee) and endinspiration (Tdi,ei), and thickening fraction (TFdi) was calculated offline as (Tdi,ei-Tdi,ee)/Tdi,ee. Two observers blinded to the results of phrenic nerve stimulation performed diaphragm ultrasound. As previously reported elsewhere [3], the reproducibility of ultrasound measurements was assessed on the first 20 patients while the two observers were blinded to each other's measurements and after they performed at least 20 diaphragm ultrasounds during a 2-month training period before starting the study $[3,17]$. Intra-class correlation (ICC) for Tdi,ei, Tdi,ee and TFdi were, respectively: ICC $=0.95(p<0.001)$, $\mathrm{ICC}=0.96(p<0.001)$ and $\mathrm{ICC}=0.87(p<0.001)[3]$.

\section{Study design}

After obtaining study measurements, patients underwent a SBT. During the SBT, patients were ventilated with a pressure support level $7 \mathrm{cmH}_{2} \mathrm{O}$ and $0 \mathrm{cmH}_{2} \mathrm{O}$ end-expiratory pressure for $30 \mathrm{~min}$. Failure of the SBT was defined if patients developed criteria for clinical intolerance defined as follows [18]: (1) pulsed oxygen saturation $<90 \%$ with a fraction of inspired oxygen $\geq 50 \%$, acute respiratory distress (respiratory rate $\geq 40 / \mathrm{min}$ with agitation or cyanosis), systolic arterial blood pressure $\geq 180 \mathrm{mmHg}$, or $\mathrm{pH}<7.32$ with an arterial carbon dioxide tension $\geq 50 \mathrm{mmHg}$. For patients with multiple failed SBT, only their first SBT was considered for the analysis.

\section{Statistical analysis}

Continuous variables are expressed as median (interquartile range), and categorical variables are expressed as absolute and relative frequency. Continuous variables were compared with Mann-Whitney $U$ test.

The manuscript conforms to the STARD checklist for reporting of studies of diagnostic accuracy [20]. Receiver operating characteristic (ROC) curves were constructed 
to evaluate the performance of the two index to predict SBT failure: Ptr,stim and TFdi. Sensitivities, specificities, positive and negative predictive values, positive and negative likelihood ratios and areas under the ROC curves (AUC-ROC) were calculated. AUC-ROC were performed to identify optimal cutoff values of Ptr,stim and TFdi in predicting SBT failure, and these estimates were obtained using bootstrapping with 1000 replications. The best threshold value for each index was determined as the value associated with the best Youden index for the prediction of SBT failure. AUC-ROC were compared using the nonparametric approach of DeLong et al. [21].

\section{Table 1 Patient's characteristics at inclusion}

\begin{tabular}{|c|c|}
\hline \multicolumn{2}{|l|}{ Characteristics } \\
\hline Female, $n(\%)$ & $24(32)$ \\
\hline Age, years & $58(48-68)$ \\
\hline SOFA & $5(4-7)$ \\
\hline Duration of mechanical ventilation, days & $4(2-6)$ \\
\hline \multicolumn{2}{|l|}{ Main reason for mechanical ventilation, $n(\%)$} \\
\hline Acute respiratory failure & $28(37)$ \\
\hline Shock & $24(32)$ \\
\hline Coma & $23(31)$ \\
\hline \multicolumn{2}{|l|}{ Ventilator parameters } \\
\hline Pressure support level, $\mathrm{cmH}_{2} \mathrm{O}$ & $10(8-10)$ \\
\hline Tidal volume, ml/kg ideal body weight & $7(5-8)$ \\
\hline PEEP, $\mathrm{cmH}_{2} \mathrm{O}$ & $5(5-6)$ \\
\hline \multicolumn{2}{|l|}{ Clinical parameters } \\
\hline Breaths, $\min ^{-1}$ & $22(20-25)$ \\
\hline Mean arterial pressure, $\mathrm{mmHg}$ & $80(69-98)$ \\
\hline Heart rate, $\min ^{-1}$ & $89(78-100)$ \\
\hline \multicolumn{2}{|l|}{ Arterial blood gases } \\
\hline $\mathrm{pH}$ & $7.44(7.40-7.45)$ \\
\hline $\mathrm{PaCO}_{2}, \mathrm{mmHg}$ & $38(34-44)$ \\
\hline $\mathrm{PaO}_{2} / \mathrm{FiO}_{2}$ & $279(214-357)$ \\
\hline
\end{tabular}

Continuous variables are expressed as median (interquartile range), and categorical variables are expressed as absolute value (\%)

SOFA sequential organ failure assessment, PEEP positive end-expiratory pressure, $\mathrm{PaO}_{2} / \mathrm{FiO}_{2}$ ratio of arterial oxygen tension to inspired oxygen fraction
For all final comparisons, a two-tailed $p$ value less than or equal to 0.05 was considered statistically significant. Statistical analyses were performed with MedCalc (MedCalc Software bvba).

\section{Results}

Between November 1, 2014, and July 31, 2015, 330 patients were admitted in our ICU. One hundred and eighty-four patients received invasive mechanical ventilation for more than $24 \mathrm{~h}$ leading to the enrollment of 76 consecutive patients in the study (Additional file 1: Figure E1. Flowchart of the study). The characteristics of these patients upon inclusion are given in Table 1.

Forty-eight patients $(63 \%)$ passed the SBT and were subsequently extubated, while 28 patients $(37 \%)$ developed criteria for SBT failure and initial ventilator settings were accordingly resumed. Of the 48 extubated patients, seven patients required resumption of ventilatory support (six were reintubated and 1 had curative noninvasive ventilation) within $48 \mathrm{~h}$ : five patients for respiratory distress and two patients for loss of consciousness. No stridor was reported. Prophylactic noninvasive ventilation was used in two patients.

\section{Prediction of spontaneous breathing trial failure} Median Ptrstim was 8.2 (5.9-12.6) $\mathrm{cmH}_{2} \mathrm{O}$; Ptr,stim was $10.0(7.3-14.3)$ and $6.5(3.0-8.8) \mathrm{cmH}_{2} \mathrm{O}$ in patients with successful and failed SBT, respectively $(p<0.001)$. The optimal threshold value of Ptr,stim to predict SBT failure was $7.2 \mathrm{cmH}_{2} \mathrm{O}$ (Table 2). A Ptr,stim value lower than $11 \mathrm{cmH}_{2} \mathrm{O}$ (the traditional cutoff for diaphragm dysfunction) predicted SBT failure with a sensitivity of $89 \%(95 \%$ CI $72-98 \%)$ and a specificity of $45 \%$ (95\% CI 30-60\%). Patients with SBT success and SBT failure according to both 7.0 and $11.0 \mathrm{cmH}_{2} \mathrm{O}$ thresholds of Ptr,stim are shown in Fig. 1a, b.

Median TFdi was 28\% (19-35) in the whole population; TFdi was 33\% (29-43) and 19\% (11-25) in patients with successful SBT and SBT failure, respectively $(p<0.001)$. The optimal threshold value of TFdi to predict

Table 2 Threshold, area under the receiver operating characteristics curves (AUC-ROC), sensitivity, specificity, positive and negative likelihood ratios and positive and negative predictive values of endotracheal pressure induced by a bilateral phrenic nerve stimulation (Ptr,stim) and diaphragm thickening fraction (TFdi) to predict weaning failure from mechanical ventilation

\begin{tabular}{|c|c|c|c|c|c|c|c|c|}
\hline & \multirow[t]{2}{*}{ Threshold } & \multirow[t]{2}{*}{ AUC-ROC (95\% Cl) } & \multirow[t]{2}{*}{ Sensitivity (\%) (95\% CI) } & \multirow[t]{2}{*}{ Specificity (\%) $(95 \% \mathrm{Cl})$} & \multicolumn{2}{|c|}{$\begin{array}{l}\text { Likelihood ratios }(95 \% \\
\text { Cl) }\end{array}$} & \multicolumn{2}{|c|}{$\begin{array}{l}\text { Predictive values (\%) } \\
(95 \% \mathrm{CI})\end{array}$} \\
\hline & & & & & Positive & Negative & Positive & Negative \\
\hline Ptr,stim & $7.2 \mathrm{cmH}_{2} \mathrm{O}$ & $0.80(0.70-0.89)$ & $68(47-84)$ & $79(64-89)$ & $3.2(1.7-5.8)$ & $0.4(0.2-0.7)$ & $66(51-78)$ & $80(70-88)$ \\
\hline TFdi & $25.8 \%$ & $0.82(0.73-0.93)$ & 79 (59-92) & $73(58-85)$ & $2.9(1.8-4.8)$ & $0.3(0.1-0.6)$ & $63(51-74)$ & $85(74-92$ \\
\hline
\end{tabular}

Cl confidence interval 

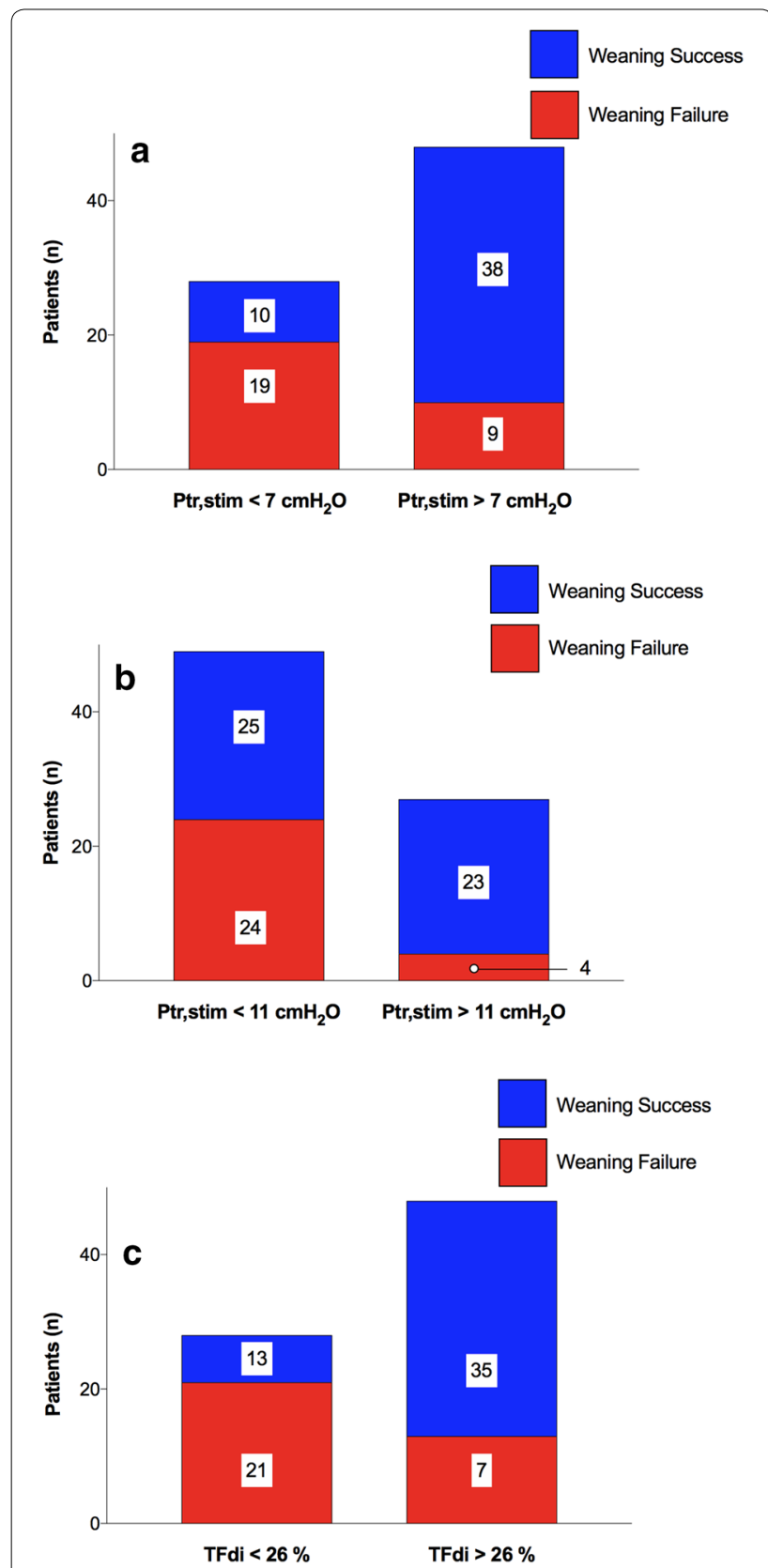

Fig. 1 Patients with successful spontaneous breathing trial and failed spontaneous breathing trial according to $7 \mathrm{cmH}_{2} \mathrm{O}$ (a) and $11 \mathrm{cmH}_{2} \mathrm{O}$ (b) thresholds of endotracheal pressure induced by a bilateral phrenic nerve stimulation (Ptr,stim) and 26\% (c) threshold of diaphragm thickening fraction (TFdi). Numbers indicate the number of patients in each category

SBT failure was $25.8 \%$. Figure 1c shows the number of patients with SBT success and SBT failure according to 25.8\%-TFdi threshold. Predictive performances of TFdi are shown in Table 2. The comparison of AUC-ROC of Ptr,stim and TFdi is displayed in Fig. 2. Ptr,stim and TFdi had similar AUC-ROC $(p=0.83)$.

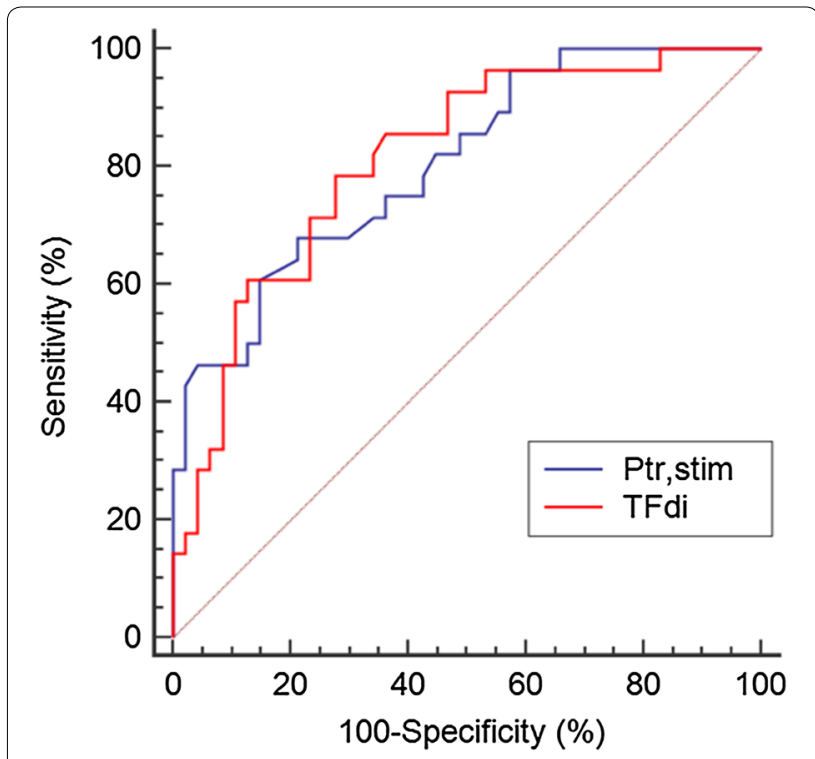

Fig. 2 Receiver operating characteristics curves of endotracheal pressure induced by a bilateral phrenic nerve stimulation (Ptr,stim) and diaphragm thickening fraction (TFdi) to predict failure of the spontaneous breathing trial

\section{Discussion}

This study reports a dual assessment of diaphragm function and its relationship with weaning outcome in mechanically ventilated medical patients undergoing a first spontaneous breathing trial. Our findings can be summarized as follows: (1) a lower value of Ptr,stim (i.e., $7.0 \mathrm{cmH}_{2} \mathrm{O}$ ) than the value commonly accepted value to define diaphragm dysfunction (i.e., $11.0 \mathrm{~cm} \mathrm{H}_{2} \mathrm{O}$ ) is more reliable to predict SBT failure, (2) Ptr,stim and TFdi are equivalent to predict SBT failure.

\section{Diaphragm function and weaning from mechanical ventilation}

The negative impact of diaphragm dysfunction on successful weaning from mechanical ventilation has been established by several investigations in critically ill patients $[3,4,11,22]$. At the time of weaning, diaphragm dysfunction is highly prevalent [1] with reported rates ranging from $25-30 \%[11,22]$ to $60-80 \%[3,4]$. To our knowledge, only three studies have assessed diaphragm dysfunction at the time of attempted liberation from mechanical ventilation using the gold standard technique, namely the phrenic nerves stimulation $[3,4,23]$. However, none of them provided any threshold values for Ptr,stim to predict weaning outcome. Of note, these studies including ours indicate that a substantial proportion of patients (up to 44\%) can be successfully weaned from the ventilator despite having diaphragm dysfunction defined as Ptr,stim $<11 \mathrm{cmH}_{2} \mathrm{O}$ [3, 4]. Therefore, 
normal diaphragm function according to a definition established in healthy subjects [12] is not a prerequisite for a successful SBT. This finding is not altogether surprising as many patients with chronic diaphragm dysfunction do not require mechanical ventilation $[24,25]$. While diaphragm dysfunction might limit exercise capacity, the clinical consequences of diaphragm dysfunction in successfully liberated patients are uncertain. However, the impact of respiratory muscles dysfunction (not specifically the diaphragm) after critical illness may be of importance since it is associated with worse long-term outcomes [26, 27]. Overall, our findings are of importance since they highlight that presence of diaphragm dysfunction at the time of weaning should not discourage clinicians from attempting liberation from ventilation. By contrast, not all patients (23/27) with a Ptr,stim higher than $11.0 \mathrm{cmH}_{2} \mathrm{O}$ had a successfully SBT. As a matter of fact, the $11.0 \mathrm{cmH}_{2} \mathrm{O}$ threshold of Ptr,stim was associated with a lower specificity but a higher sensitivity than the $7.0 \mathrm{cmH}_{2} \mathrm{O}$ threshold in the prediction of SBT failure. The lower $7.0 \mathrm{cmH}_{2} \mathrm{O}$ Ptr,stim threshold provides the optimal combination of sensitivity and specificity in the prediction of SBT failure.

\section{Diaphragm ultrasound in the prediction of SBT failure}

The use of diaphragm ultrasound is growing in the ICU $[28,29]$. It has many advantages over phrenic nerve stimulation, which requires costly equipment and extensive technical expertise. Ultrasound is a noninvasive and highly feasible bedside imaging modality, and ultrasound devices are widely available in ICUs. Several studies have proposed various ultrasound-derived markers aiming at assessing diaphragm function. Importantly, in our study, Ptr,stim and TFdi demonstrated similar performance in the prediction of weaning. Of note, the optimal TFdi cutoff (26\%) identified in our study is very close to the cutoffs reported in previous investigations [16, 30,31]. Considering ultrasound as a substitute of the phrenic nerves stimulation technique, it will make diaphragm evaluation much easier at the bedside. However, the indication of diaphragm ultrasound during the weaning process is not yet clearly defined. In addition, it is important to remind that the majority of patients are shortly and safely separated from the ventilation. As it happens, the place of diaphragm ultrasound might be viewed as a complementary investigation and not as a surrogate of clinical judgment. It may be used as a screening tool to identify patients who are at high risk of SBT failure (before conducting the SBT) or as a diagnostic method to determine the cause of SBT or extubation failure [32].

\section{Strengths and limitations of our study}

This study is the largest to report a dual approach providing comparison between the gold standard evaluation method of diaphragm function and diaphragm ultrasound during the weaning phase. However, this study has limitations. First, the generalizability of our findings may be limited by the characteristics of the patients of our cohort. Accordingly, our study might be viewed as a hypothesis generator and further trials are warranted to confirm the clinical relevance of our findings. Second, while we obtained good inter- and intra-reproducibility in the measurements of diaphragm ultrasound, centers employing the technique must also demonstrate adequate technical skill (based on reproducibility) before implementing the technique for clinical purposes. Third, we performed diaphragm ultrasound while patients were ventilated with pressure support and not during the SBT. While this approach is easier to implement (no change in ventilator setting) and less stressful for patients, it could underestimate diaphragm thickening [33]. However, the amount of pressure support was standardized in order to target a tidal volume between 6 and $8 \mathrm{ml} / \mathrm{kg}$ predicted body weight. Reassuringly, any effect of ventilatory support on TFdi is likely to introduce 'noise' in its correlation with weaning outcome and this would tend to bias the observed association toward the null. Fourth, we have assessed diaphragm function by using the changes in tracheal twitch pressure rather than the changes in transdiaphragmatic twitch pressure. This last measurement is more specific to the diaphragm function but requires the placement of two balloons, which make it more invasive. Although the two twitch pressures are not interchangeable, they are well correlated [15].

\section{Conclusions}

Diaphragm ultrasound is a reliable surrogate of the phrenic nerve stimulation method in the assessment of diaphragm function to predict weaning outcome. A multicenter investigation is now required to confirm whether the $26 \%$ value of TFdi cutoff could or could not be used widely to predict SBT outcome. Diaphragm ultrasound could be combined with cardiac echo or lung ultrasound to tailor post-extubation management according to the risk of weaning failure. Although diaphragm dysfunction did not systematically impair weaning outcome, it may behave as a marker of severity and poor prognosis. Future studies should address this hypothesis and investigate mid- and long-term consequences of diaphragm dysfunction on patient functional status and quality of life. 


\section{Additional file}

Additional file 1. Full description of the Methods. Figure E1. Flow chart of the patients.

\section{Abbreviations}

SBT: Spontaneous breathing trial; Ptr,stim: Tracheal pressure in response to bilateral magnetic stimulation of the phrenic nerves; TFdi: Diaphragm thickening fraction; ICU: Intensive care unit; AUC-ROC: Area under the curve of receiving operating characteristics.

\section{Authors' contributions}

$M D$ and $A D$ designed the study. MD, AD, BPD and TS coordinated the study. $M D, B P D, D R, E M, L D$ and JM were responsible for patient screening, enrollment, and follow-up. MD, AD, EG and TS analyzed the data. MD, AD, EG and TS wrote the manuscript. All authors had full access to all study data, contributed to drafting the manuscript or critical revision of it for important intellectual content, approved the final version of the manuscript, and took responsibility for the integrity of the data and the accuracy of the data analysis. All authors read and approved the final manuscript.

\section{Author details}

${ }^{1}$ UPMC Univ Paris 06, INSERM, UMRS1158, Neurophysiologie Respiratoire Expérimentale et Clinique, Sorbonne Universités, Paris, France. ${ }^{2}$ Service de Pneumologie et Réanimation Médicale (Département "R3S"), AP-HP, Groupe Hospitalier Pitié-Salpêtrière Charles Foix, 47-83 boulevard de l'Hôpital, 75013 Paris, France. ${ }^{3}$ Interdepartmental Division of Critical Care Medicine, University of Toronto, Toronto, Canada. ${ }^{4}$ Division of Respirology, Department of Medicine, University Health Network and Mount Sinai Hospital, Toronto, Canada. ${ }^{5}$ Département de Médecine, Service de Pneumologie, Hôpital Hôtel-Dieu, Centre Hospitalier de l'Université de Montréal (CHUM), Montréal, QC, Canada.

\section{Acknowledgements}

None.

\section{Competing interests}

Alexandre Demoule has signed research contracts with Medtronic, Maquet and Philips; he has also received personal fees from Medtronic, Maquet, Resmed, Fisher \& Paykel and MSD. Martin Dres received personal fees from Pulsion Medical System and Lungpacer Inc. Bruno-Pierre Dubé has received honoraria from GlaxoSmithKline, Boehringer Ingelheim, Astra Zeneca and Roche. Relevant to the present study, Thomas Similowski has received personal fees from Lungpacer Inc and is a member of the board of a research association that has received, over the past 10 years, unrestricted research grants from Maquet, Hamilton, Covidien, and Philips; he is the head of a research unit (UMRS 1158) that has signed research contracts with Air Liquide Medical Systems, France; he is listed as inventor or co-inventor on several patents, granted or pending, describing a brain-ventilator interface. The other authors have no conflict of interest relevant to this study.

\section{Availability of data and materials}

The datasets used and/or analyzed during the current study are available from the corresponding author on reasonable request.

\section{Consent for publication}

Patients or their next of kin gave informed consent.

\section{Ethics approval and consent to participate}

Human research ethics committee approval for the study was provided by the Comité de Protection des Personnes-lle de France 6.

\section{Funding}

M.D. was supported by the French Intensive Care Society, Paris, France (bourse de mobilité 2015); The 2015 Short Term Fellowship program of the European Respiratory Society, Lausanne, Switzerland; The 2015 Bernhard Dräger Award for advanced treatment of acute respiratory failure of the European Society of Intensive Care Medicine, Brussels, Belgium; the Assistance Publique Hôpitaux de Paris, Paris, France and the Fondation pour la Recherche Médicale, Paris, France (FDM 20150734498).

\section{Publisher's Note}

Springer Nature remains neutral with regard to jurisdictional claims in published maps and institutional affiliations.

Received: 2 February 2018 Accepted: 16 April 2018

Published online: 23 April 2018

\section{References}

1. Dres M, Goligher EC, Heunks LMA, Brochard LJ. Critical illness-associated diaphragm weakness. Intensive Care Med. 2017:43:1441-52.

2. Demoule A, Jung B, Prodanovic H, Molinari N, Chanques G, Coirault C, et al. Diaphragm dysfunction on admission to the intensive care unit. Prevalence, risk factors, and prognostic impact-a prospective study. Am J Respir Crit Care Med. 2013;188:213-9.

3. Dres M, Dubé B-P, Mayaux J, Delemazure J, Reuter D, Brochard L, et al. Coexistence and impact of limb muscle and diaphragm weakness at time of liberation from mechanical ventilation in medical intensive care unit patients. Am J Respir Crit Care Med. 2017;195:57-66.

4. Jung B, Moury PH, Mahul M, de Jong A, Galia F, Prades A, et al. Diaphragmatic dysfunction in patients with ICU-acquired weakness and its impact on extubation failure. Intensive Care Med. 2016;42:853-61.

5. Jaber S, Petrof BJ, Jung B, Chanques G, Berthet J-P, Rabuel C, et al. Rapidly progressive diaphragmatic weakness and injury during mechanical ventilation in humans. Am J Respir Crit Care Med. 2011;183:364-71.

6. Levine S, Nguyen T, Taylor N, Friscia ME, Budak MT, Rothenberg P, et al. Rapid disuse atrophy of diaphragm fibers in mechanically ventilated humans. N Engl J Med. 2008;358:1327-35.

7. Hermans G, Agten A, Testelmans D, Decramer M, Gayan-Ramirez G. Increased duration of mechanical ventilation is associated with decreased diaphragmatic force: a prospective observational study. Crit Care Lond Engl. 2010;14:R127.

8. Vassilakopoulos T, Petrof BJ. Ventilator-induced diaphragmatic dysfunction. Am J Respir Crit Care Med. 2004;169:336-41.

9. Heunks LMA, Doorduin J, van der Hoeven JG. Monitoring and preventing diaphragm injury. Curr Opin Crit Care. 2015;21:34-41.

10. Supinski GS, Callahan LA. Diaphragm weakness in mechanically ventilated critically ill patients. Crit Care Lond Engl. 2013;17:R120.

11. Kim WY, Suh HJ, Hong S-B, Koh Y, Lim C-M. Diaphragm dysfunction assessed by ultrasonography: influence on weaning from mechanical ventilation. Crit Care Med. 2011;39:2627-30.

12. American Thoracic Society/European Respiratory Society. ATS/ERS statement on respiratory muscle testing. Am J Respir Crit Care Med. 2002;166:518-624.

13. Mills GH, Kyroussis D, Hamnegard CH, Polkey Ml, Green M, Moxham J. Bilateral magnetic stimulation of the phrenic nerves from an anterolateral approach. Am J Respir Crit Care Med. 1996;154:1099-105.

14. Mills GH, Ponte J, Hamnegard CH, Kyroussis D, Polkey MI, Moxham J, et al. Tracheal tube pressure change during magnetic stimulation of the phrenic nerves as an indicator of diaphragm strength on the intensive care unit. Br J Anaesth. 2001;87:876-84.

15. Watson AC, Hughes PD, Louise Harris M, Hart N, Ware RJ, Wendon J, et al. Measurement of twitch transdiaphragmatic, esophageal, and endotracheal tube pressure with bilateral anterolateral magnetic phrenic nerve stimulation in patients in the intensive care unit. Crit Care Med. 2001;29:1325-31

16. DiNino E, Gartman EJ, Sethi JM, McCool FD. Diaphragm ultrasound as a predictor of successful extubation from mechanical ventilation. Thorax. 2014;69:423-7.

17. Dubé B-P, Dres M, Mayaux J, Demiri S, Similowski T, Demoule A. Ultrasound evaluation of diaphragm function in mechanically ventilated patients: comparison to phrenic stimulation and prognostic implications. Thorax. 2017;72:811-8. 
18. Boles J-M, Bion J, Connors A, Herridge M, Marsh B, Melot C, et al. Weaning from mechanical ventilation. Eur Respir J Off J Eur Soc Clin Respir Physiol. 2007;29:1033-56.

19. Similowski T, Yan S, Gauthier AP, Macklem PT, Bellemare F. Contractile properties of the human diaphragm during chronic hyperinflation. $\mathrm{N}$ Engl J Med. 1991;325:917-23.

20. Bossuyt PM, Cohen JF, Gatsonis CA, Korevaar DA, STARD group. STARD. updated reporting guidelines for all diagnostic accuracy studies. Ann Transl Med. 2015;2016(4):85.

21. DeLong ER, DeLong DM, Clarke-Pearson DL. Comparing the areas under two or more correlated receiver operating characteristic curves: a nonparametric approach. Biometrics. 1988;44:837-45.

22. Jiang J-R, Tsai T-H, Jerng J-S, Yu C-J, Wu H-D, Yang P-C. Ultrasonographic evaluation of liver/spleen movements and extubation outcome. Chest. 2004;126:179-85.

23. Laghi F, Cattapan SE, Jubran A, Parthasarathy S, Warshawsky P, Choi Y-SA, et al. Is weaning failure caused by low-frequency fatigue of the diaphragm? Am J Respir Crit Care Med. 2003;167:120-7.

24. Manders E, Bonta PI, Kloek JJ, Symersky P, Bogaard H-J, Hooijman PE, et al. Reduced force of diaphragm muscle fibers in patients with chronic thromboembolic pulmonary hypertension. Am J Physiol Lung Cell Mol Physiol. 2016;311:L20-8.

25. Kelley RC, Ferreira LF. Diaphragm abnormalities in heart failure and aging: mechanisms and integration of cardiovascular and respiratory pathophysiology. Heart Fail Rev. 2017;22:191-207.

26. Adler D, Dupuis-Lozeron E, Richard J-C, Janssens J-P, Brochard L. Does inspiratory muscle dysfunction predict readmission after intensive care unit discharge? Am J Respir Crit Care Med. 2014;190:347-50.
27. Medrinal C, Prieur G, Frenoy É, Robledo Quesada A, Poncet A, Bonnevie $T$, et al. Respiratory weakness after mechanical ventilation is associated with one-year mortality - a prospective study. Crit Care Lond Engl. 2016:20:231.

28. Zambon M, Greco M, Bocchino S, Cabrini L, Beccaria PF, Zangrillo A. Assessment of diaphragmatic dysfunction in the critically ill patient with ultrasound: a systematic review. Intensive Care Med. 2017;43:29-38.

29. Haaksma M, Tuinman PR, Heunks L. Ultrasound to assess diaphragmatic function in the critically ill-a critical perspective. Ann Transl Med. 2017;5:114

30. Ferrari G, De Filippi G, Elia F, Panero F, Volpicelli G, Aprà F. Diaphragm ultrasound as a new index of discontinuation from mechanical ventilation. Crit Ultrasound J. 2014;6:8.

31. Dres M, Demoule A. Diaphragm dysfunction during weaning from mechanical ventilation: an underestimated phenomenon with clinical implications. Crit Care Lond Engl. 2018;22:73.

32. Mayo P, Volpicelli G, Lerolle N, Schreiber A, Doelken P, Vieillard-Baron A. Ultrasonography evaluation during the weaning process: the heart, the diaphragm, the pleura and the lung. Intensive Care Med. 2016:42:1107-17.

33. Blumhof S, Wheeler D, Thomas K, McCool FD, Mora J. Change in diaphragmatic thickness during the respiratory cycle predicts extubation success at various levels of pressure support ventilation. Lung. 2016;194:519-25.

\section{Submit your manuscript to a SpringerOpen ${ }^{\circ}$ journal and benefit from:}

- Convenient online submission

- Rigorous peer review

- Open access: articles freely available online

- High visibility within the field

- Retaining the copyright to your article

Submit your next manuscript at $\boldsymbol{\nabla}$ springeropen.com 